\title{
Effect of mother's education on child's nutritional status in the slums of Nairobi
}

\author{
Benta A Abuya ${ }^{1 *}$, James Ciera ${ }^{1,2}$ and Elizabeth Kimani-Murage ${ }^{3}$
}

\begin{abstract}
Background: Malnutrition continues to be a critical public health problem in sub-Saharan Africa. For example, in East Africa, $48 \%$ of children under-five are stunted while $36 \%$ are underweight. Poor health and poor nutrition are now more a characteristic of children living in the urban areas than of children in the rural areas. This is because the protective mechanism offered by the urban advantage in the past; that is, the health benefits that historically accrued to residents of cities as compared to residents in rural settings is being eroded due to increasing proportion of urban residents living in slum settings. This study sought to determine effect of mother's education on child nutritional status of children living in slum settings.

Methods: Data are from a maternal and child health project nested within the Nairobi Urban Health and Demographic Surveillance System (NUHDSS). The study involves 5156 children aged 0-42 months. Data on nutritional status used were collected between October 2009 and January 2010. We used binomial and multiple logistic regression to estimate the effect of education in the univariable and multivariable models respectively.

Results: Results show that close to $40 \%$ of children in the study are stunted. Maternal education is a strong predictor of child stunting with some minimal attenuation of the association by other factors at maternal, household and community level. Other factors including at child level: child birth weight and gender; maternal level: marital status, parity, pregnancy intentions, and health seeking behaviour; and household level: social economic status are also independently significantly associated with stunting.
\end{abstract}

Conclusion: Overall, mothers' education persists as a strong predictor of child's nutritional status in urban slum settings, even after controlling for other factors. Given that stunting is a strong predictor of human capital, emphasis on girl-child education may contribute to breaking the poverty cycle in urban poor settings.

Keywords: Education, Child stunting, Health, Urban slum, Kenya

\section{Background}

Malnutrition, particularly stunting, is still a severe public health problem in Sub-Saharan Africa [1]. For example, about $35 \%$ of preschoolers are stunted, while $29 \%$ are underweight in Sub-Saharan Africa [2]. In addition, the Fifth Global Nutritional Report estimates that in East Africa $44 \%$ of children under-five were stunted while $31 \%$ were underweight in 2005 [3]. Malnutrition has both short term and long term adverse ramifications. In the short-term for the individual, it is associated with ill health and mortality [4]. In the long-term, it leads

\footnotetext{
*Correspondence: atienoa6@gmail.com

'Education Research Program, African Population \& Health Research Center (APHRC), Kirawa Road, Off Peponi Road, P.O. Box 10787, 00100 Nairobi, Kenya Full list of author information is available at the end of the article
}

to impaired cognitive development, poorer educational achievement and economic productivity $[5,6]$.

Rapid growth in urban population has been experienced in the entire world in recent decades. For instance, the population in cities in the developing countries was 2 billion in 2000 and is expected to rise to about 4 billion in 2030 [7]. This rapid and uncontrolled urbanization in many Sub-Saharan African countries, Kenya included has resulted in a vast majority of people in urban areas living in slum conditions. The slums are characterized by overcrowding, filth, inadequate water supply, poor drainage, and poverty; leading to poor health for the urban dwellers [8,9]. According to Gould (1998), the effects of the unhealthy slum conditions and congestion include diarrhoea outbreaks for long periods of time which leads to instances of malnutrition, poor 
health, and death among young children [10]. According to Haddad et al, the urban poor and the urban underfed have increased, and will surpass those in rural areas [11]. The authors projected that in the next 20 years, there would be an increase in the urban poor, and with it would be increased levels of malnutrition. Recent research in the Kenyan context shows that ill health and poor nutrition are more common characteristics of children living in urban areas than rural areas [8]. A study using data from 15 countries showed that the urban advantage is being eroded for young children [12]. This is attributed to deterioration in conditions in urban areas rather than an improvement in rural areas. The deterioration in urban areas is attributed to the rapid population growth therein which has surpassed the provision of sanitation and health services [12-14].

\section{Women's education and child malnutrition}

Research shows that there is a strong linkage between maternal education and children's health. Children born to educated women suffer less from malnutrition which manifests as underweight, wasting and stunting in children. Maternal education has been associated with nutrition outcomes among children in studies in various settings including Jamaica [15]; Bolivia [16]; and Kenya $[17,18]$. However, the mechanisms that link mother's education and child health in general are still not well understood. Glewwe (1999) highlights three links through which education may affect child health [19]. First, formal education of mothers directly transfers health knowledge to future mothers. Second, the literacy and numeracy skills that women acquire in school enhance their ability to recognise illness and seek treatment for their children. Additionally, they are better able to read medical instructions for treatment of childhood illness and apply the treatment. Third, increased number of years in school makes women more receptive to modern medicine. Other studies have found a strong link between maternal education, social economic status and child nutritional status. This is because educated women are more likely to get steadier, higher paying jobs; to get married to men with higher education and higher income; and to live in better neighbourhoods, which have influence on child health and survival $[16,20,21]$. Studies have also found an association between maternal education and maternal depression [22], while maternal depression has been associated with poor child health outcomes, including poor nutritional outcomes [23]. Against this background, this study focuses on the urban poor in Kenya, a country that still registers a relatively high child mortality rate in Africa (74/1000 in 2008-09) [24]. Progress towards the 2015 Millennium Development Goals (MDG) targets has been slower than anticipated, the reason why there is need for further research into ways in which maternal education influences child nutrition. The purpose of this study is to better understand factors that influence poor health outcomes in the urban slums of Nairobi, Kenya. We seek to answer the question: Does mother's education affect child nutritional status in the context of urban poverty?

\section{Methods \\ Study setting}

The study was carried out in two urban informal settlements of Korogocho and Viwandani in Nairobi, Kenya. The study was nested within the Nairobi Urban Health and Demographic Surveillance System (NUHDSS) run by the African Population and Health Research Center (APHRC). The NUHDSS follows a population of slightly more than 60,000 people; $57 \%$ and $43 \%$ from Viwandani and Korogocho slum respectively. The follow up comprises of a systematic quarterly recording of vital demographic events including births, deaths and migrations occurring among residents of all households in Korogocho and Viwandani since 2003. Other data that is collected includes: household assets, morbidity, and education which is also collected and updated regularly. The two slum areas are densely populated, and characterized by high unemployment rates, lack of a basic infrastructure, poor housing, violence, insecurity, and poor health indicators $[8,25]$. The two slums are heterogeneous particularly with regards to socio-economic status: Viwandani has relatively higher levels of education and employment, high mobility of residents and split households while the population in Korogocho is more stable with greater co-residence of spouses.

\section{Data source and data collection}

This paper draws on data from the maternal and child health component of a broader longitudinal study entitled Urbanization, Poverty and Health Dynamics (UPHD) in sub-Saharan Africa, nested within the NUHDSS. The UPHD project addresses key health consequences of rapid urbanization and growing urban poverty at different stages of the life course namely childhood, adolescence, adulthood, and old age. Initially, all women who had given birth from September 2006 to January 2007, as well as their children were enrolled in the study starting in February 2007. Data were collected at baseline and updated every 4 months, at which point more mother and child pairs were enrolled. Anthropometric measurements for each child were taken during every update. Length for children aged less than 24 months was measured using a measuring board (Shorr Productions, LLC, Maryland, US) while height for those aged 24 months or more was measured using a height board (Seca 213, Seca GmbH, Germany). During each visit field interviewers administered questionnaires to collect data 
on vaccination, health care seeking and child care practices. In this study we utilize cross-sectional data of child stunting collected in the last round of data collection conducted between October 2009 and January 2010. The study involves eight sub-cohorts of children $(n=5156)$ aged 0-42 months enrolled between February 2007 and January 2010.

\section{Ethical considerations}

The Urbanization, Poverty and Health Dynamics study was approved by the Ethical Review Board of the Kenya Medical Research Institute (KEMRI). The field workers were trained in research ethics and obtained informed consent from all respondents. The NUHDSS has also been approved by KEMRI's Ethical Review Board. Verbal consent is routinely obtained from all the NUHDSS respondents.

\section{Variables and measurement}

The analysis focuses on the effect of mother's education on child stunting. The dependent variable is stunting; measured by height-for-age z-scores (HAZ). The height for age z-scores were generated using the World Health Organization (WHO) 2006 growth standards with the WHO Anthro 2005 program, Beta Version (World Health Organization, 2006). The variable was coded as "1" (stunted) if HAZ was $<-2$, and " 0 " (not stunted) if HAZ was $\geq-2$. Mother's education is the main predictor variable. The two education categories (primary education or less and secondary or higher) were coded as "1" and "0" respectively. The covariates included: child level characteristics, maternal demographic characteristics, maternal health knowledge and seeking behaviour; household characteristics and community characteristics.

\section{Child level characteristics}

Birth weight was constructed from the children's weight reported on the birth card or mother's recall. Birth weight has two categories-less than $2500 \mathrm{~g}$ and above $2500 \mathrm{~g}$. Gender of child has two categories; female and male.

\section{Maternal demographic characteristics}

Mother's age has five categories: 15-19, 20-24, 25-29, $30-34$, and 35+. The mother's marital status was coded into 3 groups: currently in union (currently married or living together), ever in union (separated, divorced, and widowed), and never married. Parity defined as the number of children per woman was divided into three categories: first birth, second birth, and third birth and above. Ethnicity comprised of five categories: Kikuyu, Luhya, Luo, Kamba and others.

\section{Maternal health knowledge and seeking behaviour}

Pregnancy intentions, used as a proxy for family planning intention was categorized as wanted now, wanted later and not at all. Number of ante-natal visits had two categories; 4 or more visits and less than 4 visits. This measure of four ante-natal visits and above is what is recommended in Kenya. Place of delivery was categorized into three categories; health facility, Traditional birth attendants (TBA/home) and others (e.g. enroute to health facility). Knowledge on when to initiate complementary foods was categorized as "yes" (coded as "0") if the mother knew that complementary foods should be initiated at 6 months as recommended by WHO, and "no" (coded as "1") if the mother said she did not know, or if she said that the foods should be initiated earlier or later than 6 months.

\section{Household characteristics}

Wealth index was constructed from household assets and amenities using principal component analysis [26]. The three wealth index categories were; low, middle, and highest.

\section{Community characteristics}

The study site was used as a proxy for community level characteristics. The variable site was coded as "0" for Viwandani and "1" for Korogocho.

\section{Analytical techniques}

The analysis was restricted to the most recent update for each child. Cross tabulation and univariable analysis was used to explore the relationship between mothers' education and child stunting as well as the effect of other covariates. Cross tabulations were used to show the distribution of the various characteristics listed above among the stunted children. In addition, univariable analysis was done in an exploratory manner to determine the effect of each factor on child stunting. The univariable models were estimated using the binomial logistic regression.

Thereafter, we conducted a multiple logistic analyses. In the multiple logistic analyses we entered all the variables that were used in the univariable analysis. However, the explanatory variables were entered sequentially in groups. The key predictor (mother's education) was entered into the model first; followed by child characteristics, maternal demographic characteristics, maternal health knowledge and healthcare seeking behavior, household characteristics and community level factors. We adjusted for clustering at the household level, to account for the nature of the data where some mothers had more than one child. Some explanatory variables had missing values for example child birth weight (34\%), maternal education $(\sim 18 \%)$, ante-natal visits $(\sim 5 \%)$, 
and social-economic status ( $10 \%)$. Imputation was done to address the missing values. We note that the household economic status was collected longitudinally in 2006, 2007, 2008 and 2009. In order to impute the missing data for social- economic status variable, we first used interpolation method to fill in the gap by computing the mean value for the existing data and substituting it for the missing household SES value. For the remaining missing data (from households that did not have SES information at any time-point (about $10 \%$ ), we used regression based imputation method to fill in the gaps.

Specifically, to generate the missing values for the variable with missing data, we used the following STATA commands to perform multiple imputation: mi impute chained (regress) for the continuous variables like child weight (34\% missing), mother's age (about $17 \%$ missing) and household SES level (before categorizing SES scores into three levels); mi impute logit for the categorical variables like mother's education level (18\% missing) and the number of ante-natal visits (about $5 \%$ missing); and mi impute mlogit for multi-category variables like ethnicity (16\% missing). The three multiple imputation methods are implemented in STATA version 12 based on different approaches used to perform multiple imputation for continuous and categorical variables [27-30]. Note, the implementation of the three set of multiple imputation commands require prior execution of the following two commands mi set and mi register which prepares and informs STATA to initialize and perform multiple imputation.

We also tested for the effects of imputation by generating a binary $(0 / 1)$ variable representing unimputed/ imputed data and including it into the model. The coefficient for the variable was not significant, an indication that the imputation process did not change the results.

\section{Results}

\section{Descriptive statistics for child stunting}

Table 1 presents percentages of stunted children by different explanatory variables. The results show that $44 \%$ of boys are stunted compared to $34 \%$ girls. Korogocho slum has slightly more stunted children with about $41 \%$ compared to Viwandani with $38 \%$. Stunting is more common among children born to single mothers and older mothers, with $45 \%$ and $46 \%$ respectively. Mothers that have at most primary level of education have $43 \%$ of their children stunted compared to $37 \%$ for mothers with at least secondary level of education. About $35 \%$ of children born to mothers who wanted to get pregnant at the time of conception were stunted compared to $44 \%$ of children born to mothers who wanted the pregnancy later, and $42 \%$ of children born to mothers who did not want to get pregnant at all. Overall, $71 \%$ of children
Table 1 Characteristics of children aged between 0-42 months in the study

\begin{tabular}{|c|c|c|c|c|}
\hline Factor & Category & $\begin{array}{l}\text { Stunted } \\
(\%)\end{array}$ & $\begin{array}{l}\text { Number } \\
\text { of Subjects }\end{array}$ & $\%$ \\
\hline \multirow[t]{2}{*}{ Child's Sex } & Male & 44.2 & 2410 & 50.5 \\
\hline & Female & 34.2 & 2360 & 49.5 \\
\hline \multirow[t]{2}{*}{ Slum } & Korogocho & 40.9 & 2490 & 52.2 \\
\hline & Viwandani & 37.5 & 2280 & 47.8 \\
\hline \multirow{2}{*}{$\begin{array}{l}\text { Mother's Education } \\
\text { level }\end{array}$} & Primary and below & 43.1 & 2,961 & 76.7 \\
\hline & Secondary + & 36.9 & 897 & 23.3 \\
\hline \multirow[t]{5}{*}{ Mother's age } & $15-19$ & 39.9 & 406 & 10.3 \\
\hline & $20-24$ & 40.1 & 1415 & 35.9 \\
\hline & $25-29$ & 42.2 & 1185 & 30.1 \\
\hline & $30-34$ & 42.9 & 564 & 14.3 \\
\hline & $35>$ & 45.6 & 373 & 9.5 \\
\hline \multirow{3}{*}{$\begin{array}{l}\text { Mother's Marital } \\
\text { Status }\end{array}$} & Currently in union & 37.8 & 3954 & 82.9 \\
\hline & Ever in union & 48.3 & 375 & 7.9 \\
\hline & Never married & 44.8 & 440 & 9.2 \\
\hline \multirow[t]{3}{*}{ Pregnancy Intentions } & Wanted now (Ref) & 35.2 & 2378 & 50.0 \\
\hline & Wanted later & 43.5 & 1773 & 37.3 \\
\hline & Not at all & 42.3 & 608 & 12.8 \\
\hline \multirow[t]{2}{*}{ Ante-natal Visits } & Less than 4 & 38.7 & 2460 & 54.9 \\
\hline & 4 or more & 38.5 & 2018 & 45.1 \\
\hline \multirow[t]{3}{*}{ Place of delivery } & Health Facility & 37.4 & 3390 & 71.2 \\
\hline & TBA \& Home & 44.6 & 1239 & 26.0 \\
\hline & $\begin{array}{l}\text { Others(enroute } \\
\text { to hospital) }\end{array}$ & 34.9 & 132 & 2.8 \\
\hline \multirow[t]{3}{*}{ Mother's Parity } & 1 birth & 34.5 & 1633 & 34.3 \\
\hline & 2 births & 40.6 & 1325 & 27.8 \\
\hline & 3 and above & 42.5 & 1806 & 37.9 \\
\hline \multirow[t]{2}{*}{ Child's birth weight } & Less than 2500 & 61.8 & 220 & 7.0 \\
\hline & Above 2500 & 36.2 & 2940 & 93.0 \\
\hline \multirow{2}{*}{$\begin{array}{l}\text { Knowledge when to } \\
\text { introduce other foods }\end{array}$} & No & 41.3 & 1477 & 31.0 \\
\hline & Yes & 38.4 & 3293 & 69.0 \\
\hline \multirow[t]{3}{*}{ Social Economic Status } & Lowest & 42.5 & 812 & 27.3 \\
\hline & Middle & 44.5 & 991 & 33.3 \\
\hline & Highest & 39.7 & 1172 & 39.4 \\
\hline \multirow[t]{5}{*}{ Mother's Ethnicity } & Kikuyu & 43.2 & 1057 & 26.7 \\
\hline & Luhya & 39 & 689 & 17.4 \\
\hline & Luo & 41.5 & 768 & 19.4 \\
\hline & Kamba & 42.5 & 835 & 21.1 \\
\hline & Others & 40.6 & 606 & 15.3 \\
\hline
\end{tabular}

were born in a health facility while $26 \%$ were born at home. Among those that were born in health facilities, $37 \%$ were stunted compared to $45 \%$ and $35 \%$ who were born at home/TBA and en route to hospital respectively. Mothers with three and more births had 
$43 \%$ of their children stunted compared to $41 \%$ of mothers with two births, and $35 \%$ among mothers with one birth. $62 \%$ of children who had low birth weight (less than 2500) were stunted compared to $36 \%$ of the children who were of optimal weight (above 2500).

The univariable results presented in Table 2 show that mothers education, child gender, birth weight, place of birth, slum site, mothers' marital status, pregnancy intentions and social economic status can significantly determine a child's nutritional status $(\mathrm{p}<0.05)$. Additionally, being the first born, a female of normal weight, born in a health facility, by a mother who is currently in union, who has at least secondary education, in a household that has high SES, will be protective against child malnutrition $(\mathrm{p}<0.05)$. Moreover, children born in Korogocho have a high tendency to be stunted compared to children born to mothers who live in Viwandani. However, mothers' age, number of ante-natal visits and ethnicity do not determine stunting.

\section{Multiple logistic regressions results (Effect of mother's education on child stunting)}

Table 3 presents the multiple regression results predicting the effect of mother's education on child stunting in the urban slums of Nairobi. Six models were fitted sequentially in this estimation, with an aim of observing the impact of mother's education on child's stunting and whether the impact of education is sustained when other variables (mothers' and child characteristics, household, and community level) are introduced into the model. The estimation started with a simple model-mothers' education regressed against child stunting. Thereafter, we sequentially added other grouped variables. Model 1 is the baseline model which introduces one explanatory variable, mothers' education, model 2 introduces the child characteristics, while model 3 adds mother's demographic characteristics. Model 4 adds variables related to the mothers' health knowledge and health seeking behaviours. Model 5 and 6 add household and community characteristics respectively.

Model 1 indicates that child stunting is significantly related to the mothers' education level $(\mathrm{p}<0.01)$. The odds of child stunting are $29 \%$ higher for mothers with no education or lower than secondary education, relative to mothers that have at least secondary education. Addition of child characteristics (child birth weight and gender) in model 2, do not change the significance of the relationship between mothers' education and child stunting. However, both child birth weight and gender are strongly related to stunting $(\mathrm{p}<0.01$, respectively). Males have $57 \%$ higher probability of being stunted compared to girls, while children of low birth weight are close to three times more likely to be stunted relative to children of normal birth weight.
Model 3 introduces mothers' demographic characteristics (mothers' age, marital status, parity and ethnicity). The relationship between mother's education and child stunting was only slightly attenuated by the presence of these demographic characteristics. However, mothers' marital status, parity, and ethnicity are independently associated to child stunting. The odds of stunting for children born to mothers who were never married are $56 \%$ higher relative to those who are currently in union respectively $(p<0.05)$. Mother's parity was also marginally associated with stunting. The odds of stunting for children born to mothers who have two births, and three or more births are $31 \%$ and $39 \%$ higher compared to those that have one child respectively $(p<0.05)$. Model 4 controlling for both mother's health knowledge and health-related behavior (family planning intentions, ante-natal visits, place of delivery and knowledge on when weaning should be initiated) had little effect on the relationship between maternal education and child stunting. However, the timing of pregnancy (whether child was wanted at conception or later or not wanted at all) and place of delivery independently determine the nutritional status of a child. The odds of stunting for a child born to a mother who gives birth in a TBA facility or at home are $39 \%$ higher compared to giving birth in a health facility $(\mathrm{P}<0.05)$. Those children whose mothers wanted to get them later had $38 \%$ higher odds of being stunted compared to those children whose mothers wanted them at conception $(\mathrm{P}<0.05)$. The association between knowledge on when to initiate complementary feeding and child stunting was not significant $(\mathrm{p}>0.1)$.

Inclusion of the household socioeconomic status (SES) in model 5 marginally reduces the significance of the relationship between mothers' education and child stunting. However, being in middle SES category does not have significant effects on child's stunting but being in highest SES category reduces the chances of stunting among children. The introduction of SES reduces the education effect on child stunting from 1.24 to 1.22 , which is still significant at $5 \%$ significance level. Consequently, controlling for household socioeconomic status and other demographic characteristics, results in the odds for child stunting being $22 \%$ higher for mothers who have no education or lower than secondary level education relative to those who have at least secondary education level. Introduction of slum of residence in model 6 leads to a reductionon the effects of mother's education from $22 \%$ to $21 \%$, but mother's education is still significantly associated to child stunting. Slum of residence is not significantly related to child stunting. Separate models were run for community level variable (s), (Korogocho and Viwandani). The results gave almost the same effects and none of the model had significant 
Table 2 Odds ratios showing the association between mothers' education and child stunting based on univariable analysis

\begin{tabular}{|c|c|c|c|c|}
\hline Factor & Category & $\begin{array}{l}\text { Odds } \\
\text { ratio }\end{array}$ & $\begin{array}{l}95 \% \text { Conf. } \\
\text { Interval }\end{array}$ & p-values \\
\hline \multirow[t]{2}{*}{ Child's Sex } & Female (ref.) & - & & \\
\hline & Male & 1.520 & (1.353 1.710) & 0.000 \\
\hline \multirow[t]{2}{*}{ Slum } & Viwandani (ref.) & & & \\
\hline & Korogocho & 1.157 & (1.029 1.299) & 0.014 \\
\hline \multirow[t]{2}{*}{ Mother's Education } & Secondary + (ref.) & - & & \\
\hline & Primary and below & 1.281 & (1.096 1.498) & 0.002 \\
\hline \multirow[t]{5}{*}{ Mother's age } & 15-19 (ref.) & - & & \\
\hline & $20-24$ & 1.010 & (0.806 1.265) & 0.931 \\
\hline & $25-29$ & 1.099 & (0.874 1.383) & 0.419 \\
\hline & $30-34$ & 1.132 & $(0.8731 .467)$ & 0.349 \\
\hline & $35>$ & 1.261 & (0.949 1.677) & 0.11 \\
\hline \multirow[t]{3}{*}{ Mother's Marital status } & Currently in union (ref.) & - & & \\
\hline & Ever in union & 1.536 & (1.242 1.988) & 0.000 \\
\hline & Never married & 1.335 & (1.094 1.628) & 0.004 \\
\hline \multirow[t]{3}{*}{ Pregnancy Intentions } & Wanted now (ref.) & - & & \\
\hline & Wanted later & 1.420 & $\left(\begin{array}{lll}1.252 & 1.611)\end{array}\right.$ & 0.000 \\
\hline & Not at all & 1.348 & (1.124 1.616) & 0.001 \\
\hline \multirow[t]{2}{*}{ Ante natal Visits } & Above 4 (ref.) & - & & \\
\hline & Less than 4 & 1.008 & (0.893 1.138) & 0.894 \\
\hline \multirow[t]{3}{*}{ Place of delivery } & Health Facility (ref.) & - & & \\
\hline & TBA \& Home & 1.343 & (1.177 1.532) & 0.000 \\
\hline & Others & 0.894 & $(0.6211 .287)$ & 0.547 \\
\hline \multirow[t]{3}{*}{ Mother's Parity } & One birth (ref.) & - & & \\
\hline & 2 births & 1.299 & $(1.1181 .509)$ & 0.001 \\
\hline & 3 and above & 1.406 & (1.225 1.615) & 0.000 \\
\hline \multirow[t]{2}{*}{ Child's birth weight } & Above 2500 (ref.) & - & & \\
\hline & Less than 2500 & 2.848 & (2.148 3.777) & 0.000 \\
\hline \multirow[t]{2}{*}{ Knowledge when to introduce other foods } & Yes (ref.) & - & & \\
\hline & No & 1.131 & (0.999 1.281) & 0.054 \\
\hline \multirow[t]{3}{*}{ Social Economic Status } & Lowest (ref.) & - & & \\
\hline & Middle & 1.022 & $(0.9241 .131)$ & 0.674 \\
\hline & Highest & 0.843 & (0.765 0.928) & 0.000 \\
\hline \multirow[t]{5}{*}{ Mother's Ethnicity } & Kikuyu (ref.) & - & & \\
\hline & Luhya & 0.938 & $(0.8451 .041)$ & 0.229 \\
\hline & Luo & 0.927 & $(0.8371 .026)$ & 0.144 \\
\hline & Kamba & 0.996 & $(0.901$ 1.100) & 0.934 \\
\hline & Others & 0.818 & (0.735 0.910$)$ & 0.000 \\
\hline
\end{tabular}

effects of education on stunting. In addition, the interaction term between education and slum site for the combined data was not significant.

It is important to note that most covariates had high level of correlation. To account for the correlation, we computed the significance of the correlation among the variables. Results indicate that the correlation levels among covariates are high and significant (significance level below 0.05) except correlations between the sex of the child and other covariates. The observed high correlation among covariates has effects on the fitted logistic regression models. For example, at univariate levels the 
Table 3 Multivariable analysis of the association between mothers' education and child stunting - with imputed data

Factor
Mother Educt
Secondary+ (rimary and be
Child's Sex
Female (ref.)
Male
Child's Birth
Above 2500 (ref.
Less than 2500
Mother's Ag
15-19 (ref.)
20-24
25-29
30-34
$35>$

\section{Mother's Marital Status}

Curr. in union (ref.)

Ever in union

Never married

Mother's Parity

First birth (ref.)

2 births

3 and above

Mother's Ethnicity

Kikuyu (ref.)

Luhya

Luo

Kamba

Others

Number of observations

Log-Likelihood

Factor

\section{Mother's Education}

Secondary + (ref.)

Primary and below

\section{Child's Sex}

Female (ref.)

Male

\section{Child's Birth Weight}

Above 2500 (ref.)

Less than 2500

\section{Model 1}

Coef. $(95 \% \mathrm{Cl})$

$1.29(1.11,1.51)$

0.001

$1.30(1.11,1.52)$

0.001

$1.26(1.08,1.48)$

0.004

$1.57(1.40,1.77)$

0.000

$1.57(1.40,1.77)$

0.000

$2.80(2.12,3.70)$

0.000

$2.72(2.06,3.60)$

0.000

$1.03(0.83,1.27)$

0.818

$1.04(0.82,1.33)$

0.734

$1.04(0.78,1.39)$

0.787

$1.13(0.82,1.56)$

0.471

$1.47(1.18,1.84)$

0.001

$1.56(1.25,1.94)$

0.000

$1.31(1.11,1.55)$

0.002

$1.39(1.14,1.69)$

0.001

$0.91(0.75,1.11)$

0.350

$0.88(0.73,1.05)$

0.162

$1.03(0.85,1.23)$

0.781

$1.01(0.44,2.30)$

0.978

4770

$-3165.2$

Model 4

Coef. (95 \% Cl)

4770

$-3105.7$

p-val

Model 5

Coef. $(95 \% \mathrm{Cl}$ )

4770

$-3080.69$

Model 6

Coef. $(95 \% \mathrm{Cl}$ )

p-val

$1.24(1.05,1.46)$

0.010

$1.22(1.03,1.43)$

0.018

$1.21(1.02,1.43)$

0.025

0.000

$1.60(1.42,1.80)$

0.000

$1.60(1.42,1.80)$

0.000 

(Continued)

\begin{tabular}{|c|c|c|c|c|c|c|}
\hline \multicolumn{7}{|l|}{ Mother's Age } \\
\hline 15-19 (ref.) & - & & - & & - & \\
\hline $20-24$ & $1.04(0.84,1.29)$ & 0.689 & $1.05(0.85,1.30)$ & 0.655 & $1.05(0.85,1.30)$ & 0.642 \\
\hline $25-29$ & $1.10(0.86,1.41)$ & 0.426 & $1.12(0.88,1.43)$ & 0.357 & $1.12(0.88,1.44)$ & 0.349 \\
\hline $30-34$ & $1.11(0.83,1.48)$ & 0.494 & $1.12(0.84,1.51)$ & 0.437 & $1.12(0.84,1.51)$ & 0.432 \\
\hline $35>$ & $1.20(0.87,1.67)$ & 0.270 & $0.21(0.87,1.68)$ & 0.258 & $1.21(0.87,1.68)$ & 0.254 \\
\hline \multicolumn{7}{|l|}{ Mother's Marital status } \\
\hline Currently in union (ref.) & - & & - & & - & \\
\hline Ever in union & $1.41(1.13,1.77)$ & 0.003 & $1.37(1.09,1.72)$ & 0.007 & $1.36(1.09,1.71)$ & 0.007 \\
\hline Never married & $1.64(1.14,1.78)$ & 0.002 & $1.35(1.08,1.70)$ & 0.009 & $1.35(1.08,1.69)$ & 0.010 \\
\hline \multicolumn{7}{|l|}{ Mother's Parity } \\
\hline \multicolumn{7}{|l|}{ First birth (ref.) } \\
\hline 2 births & $1.23(1.04,1.47)$ & 0.016 & $1.21(1.02,1.44)$ & 0.028 & $1.21(1.02,1.44)$ & 0.028 \\
\hline 3 and above & $1.22(1.00,1.49)$ & 0.054 & $1.16(0.95,1.43)$ & 0.151 & $1.16(0.94,1.42)$ & 0.156 \\
\hline \multicolumn{7}{|l|}{ Mother's Ethnicity } \\
\hline Kikuyu (ref.) & - & & - & & - & \\
\hline Luhya & $0.83(0.68,1.01)$ & 0.063 & $0.82(0.67,1.00)$ & 0.047 & $0.74(0.67,1.00)$ & 0.047 \\
\hline Luo & $0.78(0.65,0.95)$ & 0.013 & $0.77(0.64,0.94)$ & 0.008 & $0.77(0.64,0.93)$ & 0.008 \\
\hline Kamba & $0.97(0.80,1.17)$ & 0.743 & $0.98(0.81,1.18)$ & 0.822 & $0.99(0.82,1.20)$ & 0.924 \\
\hline Others & $0.97(0.42,2.21)$ & 0.937 & $0.99(0.43,2.26)$ & 0.975 & $0.99(0.43,2.26)$ & 0.980 \\
\hline \multicolumn{7}{|l|}{ Pregnancy Intentions } \\
\hline Wanted now (ref.) & - & & - & & - & \\
\hline Wanted later & $1.38(1.20,1.58)$ & 0.000 & $1.37(1.19,1.57)$ & 0.000 & $1.36(1.19,1.56)$ & 0.000 \\
\hline Not ever wanted & $1.19(0.96,1.44)$ & 0.113 & $1.17(0.95,1.43)$ & 0.132 & $1.16(0.95,1.42)$ & 0.157 \\
\hline \multicolumn{7}{|l|}{ Ante-natal Visits } \\
\hline Above 4 (ref.) & - & & - & & - & \\
\hline Less than 4 & $0.95(0.84,1.08)$ & 0.454 & $0.95(0.83,1.07)$ & 0.398 & $0.95(0.83,1.07)$ & 0.384 \\
\hline \multicolumn{7}{|l|}{ Place of Delivery } \\
\hline \multicolumn{7}{|l|}{ Health Facility (ref.) } \\
\hline TBA \& Home & $1.39(1.20,1.61)$ & 0.000 & $1.38(1.19,1.60)$ & 0.000 & $1.39(1.20,1 \cdot 61)$ & 0.000 \\
\hline Others (enroute to hospital) & $0.98(0.67,1.42)$ & 0.903 & $1.01(0.69,1.47)$ & 0.958 & $1.02(0.70,1.50)$ & 0.905 \\
\hline \multicolumn{7}{|c|}{ Knowledge when to introduce other foods } \\
\hline Yes (ref.) & - & & - & & - & \\
\hline No & $1.07(0.94,1.22)$ & 0.299 & $1.07(0.94,1.22)$ & 0.324 & $1.07(0.94,1.22)$ & 0.317 \\
\hline \multicolumn{7}{|l|}{ Social Economic Status } \\
\hline Lowest (ref.) & - & & - & & - & \\
\hline Middle & & & $0.93(0.80,1.07)$ & 0.312 & $0.93(0.80,1.08)$ & 0.333 \\
\hline Highest & & & $0.77(0.66,0.91)$ & 0.001 & $0.78(0.66,0.66)$ & 0.002 \\
\hline \multicolumn{7}{|l|}{ Slum of Residence } \\
\hline Korogocho (ref.) & - & & - & & - & \\
\hline Viwandani & & & & & $0.96(0.84,1.11)$ & 0.590 \\
\hline Number of observations & 4770 & & 4770 & & 4770 & \\
\hline Log-Likelihood & -3055.98 & & -3050.38 & & -3050.2 & \\
\hline
\end{tabular}


site (Viwandania and Korogocho) was significantly related to stunting but at multivariate level, the variable (site) was no longer significantly related to stunting. This can be explained by high correlation that exist between the site and other variables like marital education level and age, place of delivery and social economic status of a household.

\section{Discussion and conclusions}

The objective of this study was to assess the effect of maternal education on child nutritional status in the two slums of Nairobi. The prevalence of stunting among children aged up to 42 months in these communities was close to $40 \%$. We found that mother's education is an important predictor for child stunting. Compared to other studies $[16,19,20]$, we found that the effect of mother's education on child stunting is only minimally attenuated by factors at child, maternal, household and community level. Therefore, we find a persisting significance of mother's education on child's stunting in this context.

Child level factors including sex and birth weight are independently and strongly associated with stunting. While the association between birth weight and nutritional status has been well documented and understood in sub-Saharan Africa [31,32], few studies have documented gender difference with regards to malnutrition in young children particularly in sub-Saharan Africa $[17,33]$. It has been argued that such differences occur in low socio-economic status settings [34]. Despite the strong significance of these child level factors in influencing child stunting, our study concludes that they do not substantially alter the effect of education on child stunting.

In addition to child level factors, maternal level factors including marital status, parity, ethnicity and mothers' health knowledge and health related behaviour including pregnancy intentions used as a proxy for family planning, and place of delivery used as a proxy for health seeking behaviour were significantly related to child stunting. The relationship between maternal level factors and child nutritional status has also been documented in several other studies [16]. These factors however only minimally attenuate the effect of mother's education on stunting.

The introduction of household wealth index into the model also minimally attenuates the effect of education on stunting, which somehow differs with findings from others settings $[16,20]$. Moreover, we find that SES is also significantly related to child stunting similar to findings from other studies [16,34], which found a statistically significant relationship between SES and child malnutrition. We also find that the introduction of slum residence marginally reduces the magnitude of the effect of mother's education on stunting.
Our results were limited by the absence of direct measures for family planning, SES, and community level characteristics for which proxy measures were used. In the case of SES, an index was constructed from household assets. The use of proxy measures and the construction of an index might have affected the impact of these variables on the dependent variable. Education status, the main predictor variable of interest was collected as a categorical variable. This may reduce the level of precision in measurement of the effect. Overall, our study has significant policy implications for child health in urban slums in Kenya. Evidence indicates that improving nutritional status has many benefits that cannot be overemphasized including improved health and survival, cognitive development and future human capital $[5,6,35]$. Our study has indicated that mother's education is an important predictor for child stunting. This suggests that improving mother's years of schooling may have significant influence on child nutritional status and ultimately alter the poverty cycle as stunting is a key predictor of human capital. Other factors influencing child nutritional status in the slums of Nairobi include child level factors (sex and birth weight), maternal level factors (marital status, parity, ethnicity, health knowledge and health seeking behaviour) and SES.

Inclusion of health knowledge skills in school curricula may lead to substantial improvement in child nutritional status by directly enabling the girls who are future mothers to have an improved health knowledge, practices, and health seeking behavior [19]. This study indicates that among children born in the slums, a substantial proportion was born at home or with the assistance of a TBA. This therefore indicates that many mothers do not adequately benefit from the babyfriendly hospital initiative being implemented in Kenya. The aim of the initiative is to enhance optimal breastfeeding and young child feeding practices, thus improving infant and child nutritional status [36]. The study therefore calls for awareness creation to enhance delivery at health facilities. Policies targeted at improving livelihoods of the urban poor may result in reduced malnutrition and ultimately alter the poverty cycle.

\section{Competing interests}

The authors have no competing interests financial or otherwise, arising from the publication of this article.

\section{Acknowledgements}

This study was funded by the Wellcome Trust (Grant No. 078530/Z/05/Z). We also acknowledge funding for the NUHDSS from the Rockefeller Foundation and core support for APHRC from the Rockefeller Foundation, and the William and Flora Hewlett Foundation. We would like to acknowledge Dr. Catherine Kyobutungi, for contributing to the design of the study from which data for this article were derived, and reviewing this manuscript. We would also like to thank, Dr. Alex Ezeh, Dr. Jean-Christophe Fotso, Prof Nyovani Madise and Prof. John Cleland for their contribution to the study design. We thank Dr. George Mgomella, Ms Hilda Essendi, Ms Teresa Saliku and Mr. Peter Muriuki for project coordination, and Martin Mutua for data 
cleaning and preparation of the analytical files. We are also grateful to the dedicated field and data processing teams at APHRC. We are highly indebted to the study participants.

\section{Author details}

${ }^{1}$ Education Research Program, African Population \& Health Research Center (APHRC), Kirawa Road, Off Peponi Road, P.O. Box 10787, 00100 Nairobi, Kenya. ${ }^{2}$ African Institute for Development Policy (AFIDEP), Suite \#29, Royal Offices, Mogotio Road, off Chiromo Lane, P.O. Box 14688, 00800 Westland's, Nairobi, Kenya. ${ }^{3}$ Health Systems and Challenges, African Population \& Health Research Center (APHRC), Kirawa Road, Off Peponi Road, P.O. Box 10787, 00100 Nairobi, Kenya.

\section{Authors' contributions}

BAA: Conceptualization of the idea, writing of the manuscript, finalization of manuscript in readiness for submission. JMC: Data analysis, writing of the manuscript and approval for submission. EWK-M: Design of the study, project management, writing of the manuscript and approval for submission. All authors read and approved the final manuscript.

\section{Authors information}

Benta A. Abuya is an Associate Research Scientist with the African Population and Health Research Center (APHRC), in Nairobi, Kenya. Her research interests include comparative education, education policy issues of access, equity and quality, and the linkages between education and health.

James Ciera is a Research/Knowledge translation scientist at the African Institute for Development Policy (AFIDEP) and formerly a Post-Doctoral Fellow at APHRC. James has a PhD is Statistical Sciences from University of Padova (Italy) and an Msc in Applied Statistics and Biostatistics from LimburgsUniversitair Centrum (Belgium). His research interests are in application of longitudinal data analysis and Bayesian statistics in health and education relatedproblems.

Elizabeth Wambui Kimani-Murage is an Associate Research Scientist with the African Population and Health Research Center and a Wellcome Trust Fellow. Her current research interests include maternal and child health issues, malnutrition including obesity and food security.

Received: 23 March 2011 Accepted: 21 June 2012 Published: 21 June 2012

\section{References}

1. Stephenson LS, Latham MC, Ottesen EA: Malnutrition and parasitic helminth infections. Parasitology 2000, 121(Suppl):S23-38.

2. Leenstra T, Petersen LT, Kariuki SK, Oloo AJ, Kager PA, terKuile FO: Prevalence and severity of malnutrition and age at menarche; crosssectional studies in adolescent schoolgirls in western Kenya. Eur $J$ ClinNutr 2005, 59(1):41-48.

3. United Nations: Standing Committee on Nutrition (SCN), 5th Report on the World Nutrition Situation. Geneva: United Nations; 2004.

4. World Health Organization: World Health Report 2002: Reducing Risks, Promoting Healthy Life. Geneva: WHO; 2002.

5. Victora CG, Adair L, Fall C, Hallal PC, Martorell R, Richter L, Sachdev HS: Maternal and Child Undernutrition Study G: Maternal and child undernutrition: consequences for adult health and human capital. Lancet 2008, 371(9609):340-357.

6. Grantham-McGregor S, Cheung YB, Cueto S, Glewwe P, Richter L, Strupp B: Developmental potential in the first 5 years for children in developing countries. Lancet 2007, 369(9555):60-70.

7. Department of Economic and Social Affairs, Population Division; 2003. New York: United Nations; 2004.

8. African Population and Health Research Center: Population and Health Dynamics in Nairobi Informal Settlements. Nairobi: APHRC; 2002.

9. Kimani-Murage EW, Ngindu AM: Quality of water the slum dwellers use: the case of a Kenyan slum. J Urban Health 2007, 84(6):829-838.

10. Gould WT: African mortality and the new 'urban penalty'. Health Place 1998, 4(2):171-181.

11. Haddad L, Ruel MT, Garrett JL: Are Urban Poverty and Undernutrition Growing? Some Newly Assembled Evidence. World Devel 1999, 27(11):1891-1904.
12. Fotso JC: Urban-rural differentials in child malnutrition: trends and socioeconomic correlates in sub-Saharan Africa. Health Place 2007, 13(1):205-223.

13. Brockerhoff $M$, Brennan E: The poverty of cities in developing countries. Population Devel. Rev. 1998, 24(1):75-114.

14. Lalou R, LeGrand TK: Child Mortality in the Urban and Rural Sahel. Population 1997, 9(19):147-168.

15. Handa S: Maternal Education and Child Height. Econ. Devel. Cult. Change 1999, 47(2):421-439.

16. Frost $M B$, Forste $R$, Haas DW: Maternal education and child nutritional status in Bolivia: finding the links. SocSci Med 2005, 60(2):395-407.

17. Kabubo-Mariara J, Ndenge GK, Mwabu DK: Determinants of Children's Nutritional Status in Kenya: Evidence from Demographic and Health Surveys. J Afr Econ 2008, doi:10.1093/jae/ejn024.

18. Abuya BA, Onsomu EO, Kimani JK, Moore D: Influence of Maternal Education on Child Immunization and Stunting in Kenya. Matern Child Health J 2011, 15:1389-1399. doi:10.1007/s10995-010-0670-z.

19. Glewwe P: Why Does Mother's Schooling Raise Child Health in Developing Countries? Evidence from Morocco. J. Human Res. 1999, 34(1):124-159.

20. Desai $S$, Alva $S$ : Maternal education and child health: is there a strong causal relationship? Demography 1998, 35(1):71-81.

21. Cleland JG, Van Ginneken JK: Maternal education and child survival in developing countries: the search for pathways of influence. SocSci Med 1988, 27(12):1357-1368.

22. Lorant V, Deliege D, Eaton W, Robert A, Philippot P, Ansseau M: Socioeconomic inequalities in depression: a meta-analysis. Am J Epidemiol 2003, 157(2):98-112.

23. Black MM, Baqui AH, Zaman K, El Arifeen S, Black RE: Maternal depressive symptoms and infant growth in rural Bangladesh. Am J ClinNutr 2009, 89(3):951 S-957S.

24. Kenya National Bureau of Statistics (KNBS), ICF Macro: Kenya Demographic and Health Survey 2008-09. Calverton, Maryland: KNBS and ICF Macro; 2009

25. African Population and Health Research Cente: Health and Livelihood Needs Of Residents of Informal Settlements on Nairobi City. Occasional Study Report 1. Nairobi: APHRC; 2009.

26. Filmer D, Pritchett LH: Estimating wealth effects without expenditure data-or tears: an application to educational enrollments in states of India. Demography 2001, 38(1):115-132.

27. Raghunathan $T E$, Lepkowski JM, VanHoewyk J, Solenberger P: A multivariate technique for multiply imputing missing values using a sequence of regression models. Survey Methodology 2001, 27:85-95.

28. Rubin DB: Multiple Imputation for Nonresponse in Surveys. New York: Wiley; 1987.

29. Lee KJ, Carlin JB: Multiple imputation for missing data: Fully conditional specification versus multivariate normal imputation. Am J Epidemiol 2010, 171:624-632.

30. Van Buuren S: Multiple imputation of discrete and continuous data by fully conditional specification. Stat Methods Med Res 2007, 16:219-242.

31. Hien NN, Kam S: Nutritional status and the characteristics related to malnutrition in children under five years of age in Nghean, Vietnam. J Prev Med Public Health 2008, 41(4):232-240.

32. Ukwuani FA, Suchindran CM: Implications of women's work for child nutritional status in sub-Saharan Africa: a case study of Nigeria. SocSCi Med 2003, 56(10):2109-2121.

33. Wamani H, Astrom AN, Peterson S, Tumwine JK, Tylleskar T: Boys are more stunted than girls in sub-Saharan Africa: a meta-analysis of 16 demographic and health surveys. BMC Pediatr 2007, 7:17.

34. Wamani H, Tylleskar T, Astrom AN, Tumwine JK, Peterson S: Mothers' education but not fathers' education, household assets or land ownership is the best predictor of child health inequalities in rural Uganda. Int J Equity Health 2004, 3(1):9.

35. Black RE, Allen LH, Bhutta ZA, Caulfield LE, de Onis M, Ezzati M, Mathers $C$, Rivera J: Maternal and child undernutrition: global and regional exposures and health consequences. Lancet 2008, 371(9608):243-260.

36. Ministry of Public Health and Sanitation: National Strategy on Infant and Young Child Feeding Strategy 2007-2010. Nairobi, Kenya: Ministry of Public Health and Sanitation; 2007.

doi:10.1186/1471-2431-12-80

Cite this article as: Abuya et al:: Effect of mother's education on child's nutritional status in the slums of Nairobi. BMC Pediatrics 2012 12:80. 